\title{
Fórmulas de apertura en la narrativa de tradición oral maya tojolabal ${ }^{1}$ Opening Formulas in Maya Tojolabal Oral Traditional Folktales
}

\author{
María-Cruz la Chica Delgado \\ Programa de Becas Posdoctorales, Centro de Estudios Mayas, \\ Instituto de Investigaciones Filológicas, Universidad Nacional Autónoma de México, México
}

\begin{abstract}
ReSUmEN: En este trabajo se analizan las fórmulas de apertura de un corpus de textos pertenecientes a la narrativa de tradición oral maya tojolabal, con una doble finalidad, describir sus elementos y la obligatoriedad de los mismos y analizar su función tanto literaria como pragmática. Este trabajo contribuye a probar que la narrativa tojolabal de tradición oral es un arte verbal que los propios narradores distinguen de la oralidad cotidiana mediante estas estructuras que enmarcan el comienzo y el fin de cada relato. También veremos cómo las fórmulas de apertura son estructuras convencionales con elementos comunes con cierto margen de variación compartidas por una comunidad cultural.
\end{abstract}

PALABRAS ClaVE: Tradición oral, literatura maya, tojolabal, fórmulas de apertura, arte verbal.

AвSTRACT: This paper analyzes the opening formulas of a set of Maya Tojolabal oral traditional folktales. It argues that oral traditional indigenous folktales constitute a verbal art that the narrators themselves distinguish from daily orality by framing the beginning and end of each story with these devices. The paper aims at both describing these elements and their obligatory character, and analyzing their literary as well as pragmatic function. Also, it shows how opening formulas have common elements with a certain margin of variation. All this confirms the idea that the oral narrative tradition is a conventionalized verbal art, with certain aesthetic rules and variable elements that are common to a cultural community.

KEYwoRDs: Oral tradition, Maya literature, opening formula, Tojolabal, verbal art.

ReCEPCIÓN: 26 de octubre de 2018.

ACEPTACIÓn: 2 de enero de 2019.

DOI: 10.19130/iifl.ecm.2019.54.980

\footnotetext{
${ }^{1}$ Hacemos notar que la autora utiliza la ortografía convencional del castellano para Tojol-ab'al, a saber tojolabal. El equipo editorial de Estudios de Cultura Maya desea señalar la existencia de criterios recientes para su uso, como sería la propuesta de Díaz Cruz et al. (2011) publicada en la Norma de Escritura de la Lengua Tojol-ab'al, que forma parte de los esfuerzos de planificación que un grupo de especialistas Tojol-ab'ales ha emprendido con el fin de visibilizar y empoderar su lengua. Asimismo, consideramos importante destacar que éste no es un hecho aislado en el área maya, toda vez que la Academia de las Lenguas Mayas de Guatemala en el Decreto 19 de 2003, en que se publicó la Ley de Idiomas Nacionales, reglamentó la ortografía para los nombres de las lenguas mayas de Guatemala (N. del E.).
} 


\section{Introducción}

Tojolwinik, "hombres cabales", 2 es la palabra con la que se denominan a sí mismos los tojolabales. Toj significa, en maya-tojolabal, "recto" en sentido literal y metafórico-moral (Lenkersdorf, 2010: 568-570), y winik, "hombre”, "varón” o "veinte" —significado, éste último, que refiere al número de dedos de las personas y es unidad del sistema numérico vigesimal- (Lenkersdorf, 2010: 636-637). ${ }^{3}$ En México, el 6.5\% de la población total es indígena (INEGI, 2016: 1) y dentro de sus fronteras hay 68 agrupaciones linguiísticas diferentes (INALI, 2010a: 10). Una de ellas es la tojolabal, perteneciente a la familia linguiística maya. Los tojolabales habitan en el sureste del estado de Chiapas y según los datos oficiales hay 54,201 hablantes (INALI, 2010a: 1). Este grupo cuenta con un acervo de expresiones artísticas tradicionales de muy diversos tipos que en la actualidad son el resultado de una amalgama cultural. En su narrativa de tradición oral pueden encontrarse motivos existentes hoy no sólo en otros grupos étnico-linguiísticos cercanos, como tseltales o tsotsiles, sino también en el mundo mestizo, además, por supuesto, de motivos universales. Los tojolabales tienen un acervo literario de narrativa de tradición oral amplio y rico que cuenta con textos pertenecientes a diferentes géneros y que refleja, perpetua (o contradice), legitima y explica muchos valores y costumbres tojolabales. De este modo, la concepción tojolabal acerca de la creación del mundo, los roles tradicionales de género, la relación del hombre con la naturaleza y con los animales, quedan reflejados en los textos.

Una de las características más llamativas de la narrativa de tradición oral tojolabal es la complejidad de las fórmulas de apertura y cierre que enmarcan sus textos. Además de cumplir la obligatoria función de delimitar el relato, estas fórmulas aportan gran cantidad de información que nos disponemos a analizar y que tiene que ver con los aspectos que sobre dichos relatos y su contexto parece importante señalar para los narradores a juzgar por lo reiterado de su uso.

\section{Las fórmulas en la narrativa tradicional}

La literatura de tradición oral, además de ser una forma específica de creación (González, 2003: 12), es reflejo de la cultura compartida por una colectividad. Por ello, los textos de tradición oral, ${ }^{4}$ objeto de estudio de la disciplina filológica, se

\footnotetext{
${ }^{2}$ Utilizamos la traducción que también utiliza López Moya en el título de su obra (2010).

${ }^{3}$ El numeral 'veinte' se designa con la misma palabra que 'hombre' por el hecho de que sólo los seres humanos tienen 20 dedos. La importancia de este número estriba, además, en su antiguo sistema numérico: "El sistema numeral de los mayas es vigesimal, a diferencia del decimal que nos llegó de la India por mediación de los árabes" (Lenkersdorf, 2005: 247).

4 “Narrativa”, "literatura oral", "tradición”, "oralidad", "texto”, son términos sobre los que existe una larga discusión teórica. De acuerdo con Ruth Finnegan (1992: 4-15) el énfasis en la parte meramente textual, más cercano a los estudios literarios, marca los términos "narrativa", "literatura" y
} 
convirtieron también en objeto de estudio de la antropología, al ofrecer elementos clave en la comprensión de las culturas. En este sentido, hemos de apreciar el hecho de que, cuando estudiamos la tradición oral no sólo analizamos un uso meramente estético del lenguaje en un acto comunicativo, sino la expresión sobre lo que la colectividad considera relevante, preserva y transmite de generación en generación mediante sucesivas performances.

Richard Bauman (1992: 41) define el concepto de "performance" como un modo de comunicación estéticamente marcado y elevado, enmarcado de una manera especial y emitido ante una audiencia. En este tipo de literatura, por tanto, el contexto forma parte de su misma definición. La performance es constitutiva del arte verbal, entendida como un tipo de comunicación hablada, y requiere que la audiencia asuma la responsabilidad de poseer una competencia comunicativa compartida según la cual puede evaluar la destreza en el manejo de tal competencia de los narradores (Bauman, 1975: 293).

El autor señala que todo acto de comunicación cuenta con una gama de mensajes que, implícita o explícitamente, dan instrucciones sobre cómo interpretar el resto de mensajes que se emiten. En el caso del arte verbal, las estructuras formulísticas se encontrarían dentro de este tipo de mensajes que el autor llama metacomunicativos (Bauman, 1992: 45). Si bien, décadas antes, Jakobson había distinguido entre la función metalinguística —-mensaje que habla sobre el código- y la función poética — mensaje que habla sobre el mensaje- (Jakobson, 1975: 358), Bauman va más allá enumerando una lista de elementos que distinguen un tipo de formulación que se logra mediante el empleo de una metacomunicación culturalmente convencional. Dentro de la lista de elementos que caracterizan la performance ampliamente documentados en otras culturas, el autor menciona las fórmulas especiales de apertura y cierre, y las relaciona con la apelación a la tradición que, como veremos, aparecen en el caso que nos ocupa y forman parte de las estructuras formulísticas de apertura (Bauman, 1975: 295).

Finalmente, Bauman apunta otras características de este tipo de eventos comunicativos, por un lado, que son preparados, y limitados temporal y espacialmente; y, por otro, que son instrumentos reflexivos de la expresión cultural (Bauman, 1992: 46-47): "[...] performance is formally reflexive — signification about signification - insofar as it calls attention to and involves self-conscious manipulation of the formal features of the comunicative system [...] making one at least conscious of its devices".

\footnotetext{
"texto" para referirse a este tipo de objetos de estudios, mientras que términos como "arte verbal" o "performance" inciden más en su parte contextual y en nuestro objeto de estudio en tanto que un tipo de situación comunicativa. En este trabajo, nuestra posición pretende hacer énfasis en lo literario que hay en ellos, tanto es así que trabajamos con textos transcritos y no con los registros audiovisuales donde muchos elementos de comunicación pudieran ser analizados. Sin embargo, no queremos olvidar la incidencia importantísima que en ellos tiene la situación comunicativa, por lo que la descripción de aquella parte del contexto que se considera afecta de forma importante a las estructuras formulísticas de apertura es descrita y analizada en las páginas siguientes.
} 
Si tomamos en serio la forma constitutivamente performativa de este tipo de literatura, no es de extrañar que precise un marco que la delimite y la separe del resto del habla. En este sentido, las fórmulas de apertura y cierre serían al habla cotidiana lo que el escenario teatral sería a la vida real: aquello que nos advierte de que somos espectadores de algo que se mueve en mayor o menor medida con leyes diferentes a las de la realidad.

From the above it has now become clear that the narrator must cross a border when moving from the everyday world, from reality, to the represented reality, the "other" world in which the tale takes place. This crossing therefore takes place at the start of the tale, but also at the end when the narrator again has to cross the border but now in the opposite direction from the fictional world to reality. These crossings can only be accomplished if one proceeds from an external point of view to an internal point of view and backwards (Neethling: 1982, 4).

En palabras de Marina Sanfilippo, las fórmulas de apertura y cierre "aíslan el cuento de la oralidad cotidiana" y "marcan la forma en que la obra se inserta en lo extratextual" para que pueda ser percibida como texto (Sanfilippo, 2007: 136). Esto implica que su función es, de algún modo, meta-pragmática: dice algo sobre el discurso que dice, ofrece un mensaje sobre el mensaje. ${ }^{5}$ No es de extrañar que estas fórmulas tengan también la función primordial de anunciar el monopolio del uso de la palabra por parte del narrador, que no será interrumpido por su auditorio en ningún momento de su emisión y hasta que finalice su fórmula de cierre. En definitiva, podemos afirmar que la función de las estructuras formulísticas responde más a criterios performativos que narratológicos (Sanfilippo, 2007: 159).

Sanfilippo menciona también la universalidad y la obligatoriedad de las fórmulas de apertura y cierre en la narrativa de tradición oral, así como su escaso estudio desde los estudios literarios, debido al hecho de que se ha tomado el cuento como un producto autónomo y susceptible de aislar de su contexto y situación performativa. Esto tiene como resultado que muchos investigadores hayan 'recortado' las fórmulas al pasar su registro al texto escrito. Existen muchos ejemplos de esta práctica en la narrativa de tradición oral indígena de México y, por supuesto, también en la narrativa de tradición oral tojolabal. En ocasiones, incluso, en lugar de simplemente eliminar la fórmula propia de esta lengua maya, se 'traducía' al castellano con fórmulas propias de nuestra tradición. Un ejemplo de ello es la fórmula de apertura del relato "Los hermanos rayo y relámpago" publicado en Palabras de nuestro corazón, cuya versión tojolabal original dice "Ja najate', junb'i majke'il" que, literalmente, quiere decir '[e]n el pasado, dicen que

5 "[...] la investigación metapragmática ha sido capaz de distinguir mensajes sobre mensajes (M/M) de mensajes sobre códigos (M/C). Esta noción es central para la discusión de las motivaciones metapragmáticas que llevan a los narradores tojolabales a escoger la cita sobre el reporte" (Curiel, 2016: 63). 
una vez', y que los editores han traducido con la fórmula habitual del mundo hispánico “érase una vez” (Gómez, Palazón y Ruz, 1999: 187-192).

Sanfilippo también señala como circunstancia habitual el hecho de que las fórmulas de apertura suelan ser más homogéneas entre sí que las de cierre y que, en éstas últimas, muchas veces se combinen varias. Argumenta que esta circunstancia se explica por el hecho de que las fórmulas de cierre se ven influenciadas por el curso de la emisión del narrador, por cómo haya respondido el público, por ejemplo, entre otras circunstancias extra-textuales (Sanfilippo, 2007: 140-146). La autora menciona algunos aspectos sobre la función de las fórmulas que podríamos aplicar a las que hemos analizado en este trabajo, como que la alusión a la fuente del narrador es afianzar el valor fehaciente del relato o que en las fórmulas del cuento maravilloso se mezcla realidad y ficción para afianzar el pacto narrativo (Sanfilippo, 2007: 140), como más adelante veremos en detalle.

Desde el ámbito de la linguiística, las fórmulas han sido poco estudiadas en los últimos años debido a que los estudios enmarcados en esta disciplina han tratado más el punto de vista creativo del lenguaje, mientras que las fórmulas pertenecen al ámbito imitativo del uso del lenguaje. Sin embargo, éstas constituyen una unidad de análisis linguiístico en tanto que son construcciones que tienen unas formas y una distribución relativamente constante (Corrigan, 2009: XV):

Formulae represent the flip side of creativity in language: they utilize a narrowly defined set of choices from among all the alternatives that rules of discourse, syntax, morphology and the lexicon would allow for. In sharp contrast to the creative aspects of the linguistic behavior of language users, formulae attest to the imitative aspects of this behavior (Corrigan, 2009: XV).

Como cualquier otro objeto social en el estudio de las fórmulas, una cuestión fundamental es el equilibrio entre la libertad para la variación y la limitación a la que están sometidas convencionalmente: "given that there is a system consisting of rules, how much freedom are we nonetheless allowed? Formulae are distinguished from ordinary sentences exactly by the limitedness of structural and lexical choices" (Corrigan, 2009: XXIII). Por esta laxitud tensa es por lo que la única manera de estudiarlas es de forma probabilística:

The choice of words and choice of structure in formulae do leave some latitude: they can be described only probabilistically. Similarly, rules about the stylistic and situational distribution of formulaic expressions are also less then watertight: they are more frequent in some situations than in others (Corrigan, 2009: XVI).

Este método será el que utilicemos en el presente trabajo: destacaremos los elementos más frecuentes en las estructuras formulísticas de apertura y analizaremos su frecuencia comparativamente para realizar un esbozo descriptivo al que habrán de añadirse en futuros estudios otros aspectos. 


\section{La importancia del contexto}

En este trabajo vamos a presentar los resultados de un estudio sobre las estructuras formulísticas de apertura y de cierre de la narrativa de tradición oral tojolabal, mediante el análisis descriptivo y comparativo de 37 versiones de diferentes relatos fruto de entrevistas a 17 narradores diferentes, vecinos de seis comunidades (Saltillo, San Antonio Tres Cerritos, Guadalupe Victoria, San Francisco, Lomantán y Justo Sierra), cuyas recreaciones fueron publicadas en Narrativas de tradición oral maya tojolabal (La Chica, 2017).

En dicha obra la autora explica con detalle las circunstancias de registro, las condiciones performativas de la emisión de los textos no fueron las condiciones en las que normalmente suelen emitirse. El registro que se llevó a cabo fue preparado y dispuesto, por lo que un estudio exhaustivo de la relación entre lengua y cultura para el caso que nos ocupa, según los métodos propuestos por Sherzer para lo que él llamó “etnografía del habla” (Pardo, 1998), queda pendiente. En este caso, se explicó a los narradores lo que se estaba buscando por medio de ejemplos, los narradores que dijeron conocer los relatos por los que se preguntaba u otros semejantes se dispusieron ante la cámara. Esta grabación se realizó en el patio o entrada de sus propios hogares, en lugares cercanos a éstos, en la iglesia de la comunidad o en el atrio de ésta. En algunas ocasiones la investigadora era el único auditorio; en otras, estaba también la familia más cercana del narrador o narradora, y a veces, estaban los vecinos de la comunidad, jóvenes y ancianos, prestando mayor o menor atención a las historias que se narraban. Durante la emisión de las mismas, nunca se interrumpió al narrador ni por parte de la investigadora ni por parte de ningún otro asistente. Los narradores y narradoras lo emitieron de principio a fin sin interrupción. Sobre este punto, en dicha obra se contrasta la información registrada con las conclusiones obtenidas por Jill Brody (1988):

Brody $[\ldots]$ apunta que este tipo de discurso literario tojolabal requiere respuestas de los oyentes que se intercalarían en el relato enunciado por el narrador y justifica su afirmación diciendo que en una ocasión el narrador se dirige a su oyente llamándolo 'hermano'. Sobre este punto tenemos que decir que, a lo largo de todo el corpus que fue registrado para esta investigación, no hay un solo caso en el que los narradores requirieran (ni esperaban, ni pedían) una respuesta activa formulada verbalmente por parte de los oyentes y entretejida en su propia narración. Sin embargo, sí podemos encontrar, en numerosas ocasiones, que los narradores se dirigen al auditorio de forma directa, llamándolos 'hermanos' o 'hermana', pero esto no constituye ningún ejemplo de interacción bidireccional entre transmisores y receptores, sino una mera llamada de atención. En varias ocasiones la investigadora que escribe preguntó explícitamente tanto a narradores como a oyentes si tal interacción era en algún caso esperada o requerida y la respuesta siempre fue negativa (La Chica, 2017: 29). 
Puede que la situación contextual performativa no influyera en la configuración de la trama o la elaboración de los recursos literarios, como los paralelismos, las metáforas, los diálogos, los difrasismos..., pero sí, en cambio, en el uso del (o los) vocativos que hacían referencia al auditorio ("hermanos y hermanas", por ejemplo) y que posteriormente analizaremos. Éstos, como es de esperar, se dirigían a un auditorio amplio, cuando era así efectivamente, compuesto de personas con las que no se comparten lazos consanguíneos, y quizá para ello se utilizaban fórmulas propias, no sabemos si de la narrativa tradicional o de situaciones performativas propias del ámbito de lo público, como asambleas o reuniones religiosas.

\section{Estructuras formulísticas de apertura}

Parece que las estructuras formulísticas de apertura y cierre son obligatorias en la narrativa de tradición oral tojolabal. De todas las versiones analizadas, tan sólo dos carecen de fórmula de apertura, y en una de éstas, además, el narrador no contó el relato completo, pues no lo recordaba, y sólo mencionó la anécdota. Su obligatoriedad se hace patente, además, por el hecho de que aquellos narradores que emitieron dos relatos en una sola performance incluyeron fórmulas de apertura al inicio del segundo relato emitido y diferenciándolo así nítidamente del primero, como ocurre en "El origen de los animales MLC-1" (La Chica, 2017: 119-138) y en "La mujer / El maíz y la hormiga arriera / Sombrerón y la mula MLC21" (La Chica, 2017: 61-64).

De los 17 informantes diferentes pertenecientes a seis comunidades, siete emitieron tan sólo un relato, y 10 narraron más de uno. Aquellos narradores que contaron más de un relato elaboraron estructuras formulísticas que se parecen entre sí, por lo que podríamos aventurar que la hipótesis de que el estilo de los narradores o, en su defecto, alguna característica relacionada con la región a la que pertenecen influye de forma en cierto modo estable en su configuración. Se pueden apreciar también diferencias entre las estructuras formulísticas que enmarcan las versiones de los narradores que refirieron más de una, no en el tipo de información que aportan, sino en la cantidad de información. Ello podría deberse a que estos narradores emitieron varias versiones en la misma sesión de registro. Es de esperar que, si un narrador emite tres o cuatro versiones en una sola sesión de registro, el cuidado en la elaboración de las estructuras formulísticas no sea siempre el mismo. Sin embargo, necesitaríamos muchos más ejemplos para poder medir la incidencia de esta circunstancia extra-textual de forma más o menos constante.

\section{Vocativo}

Uno de los elementos más frecuentes de la estructura formulística de apertura es el uso del vocativo para llamar la atención del público. Los narradores abren 
la estructura formulística con este elemento en 15 de las 37 versiones aquí analizadas y lo hacen utilizando siempre la palabra de origen castellano "hermano", "hermana”, en diferentes formas. Este término se utiliza en tojolabal para dirigirse cordialmente a personas con las que no se tiene relación de consanguineidad en un trato de respeto fuera del ámbito doméstico. ${ }^{6}$

De esas 15 estructuras formulísticas que hemos mencionado, 10 se abren con la fórmula "hermanos y hermanas", y se encuentran en versiones elaboradas por ocho narradores, todos ellos residentes en Guadalupe Victoria. En esta comunidad, se escuchó esta fórmula durante la misa católica cuando, tanto los misioneros como los feligreses, se dirigían al resto para expresar su pensamiento sobre los asuntos tratados. ¿Sólo en Guadalupe Victoria utilizan esta forma específica para comenzar la estructura formulística de apertura? Todo parece indicar que sí, aunque una de las narradoras era originaria de la comunidad de Puebla, cercana relativamente a Guadalupe Victoria, y también la usaba (1):

\begin{tabular}{|l|l|l|}
\hline \multicolumn{3}{|c|}{ El origen de los animales MLC-3 } \\
\hline 1 & $\begin{array}{l}\text { Pues, hermanos y hermanas, oj kala } \\
\text { awab'yex jun cuento yalunej kab' ja } \\
\text { cham jtataguielo ke'na ja najate'i. }\end{array}$ & $\begin{array}{l}\text { Pues, hermanos y hermanas, os voy a } \\
\text { decir un cuento que me tiene dicho mi } \\
\text { difunto abuelo en el pasado. }\end{array}$ \\
\hline
\end{tabular}

Ahora bien, que todo parezca indicar que es una fórmula, no quita que no tengamos fuertes razones para pensar que no es esperable en las estructuras formulísticas de apertura de la narrativa tradicional. El haber sacado los relatos de su contexto habitual, el doméstico, para ser emitidos en el ámbito público, debió influir en el hecho de que la mención al auditorio sea la misma que la del tipo de discursos que se dan en éste. Por lo que sabemos de los términos "hermano" y "hermana" en tojolabal, éstos excluyen su utilización, precisamente, entre personas con relaciones de consanguineidad, que es la relación que tienen las personas entre las cuales normalmente se emiten este tipo de relatos. No

6 “El término de origen castellano 'hermano', 'hermana' es usado en tojolabal como fórmula de salutación para abrir el canal de comunicación en distintas situaciones comunicativas no domésticas entre personas que no tienen lazos consanguíneos. Estos términos conviven con términos de parentesco nativos que en las comunidades norteñas son flexionados con el sufijo -a, de vocativo, y en las comunidades sureñas no tienen flexión alguna. Por ejemplo, watsa, 'hermana mayor', para saludar a mujeres mayores, nu'a, 'hermano mayor de una mujer', tatjuna, 'abuelo', me'juna, 'abuela', nana, 'madre', tata, 'padre', kijts'ina, 'hermano menor'. Sobre esa base, se puede concluir que no se trata de un uso del término castellano fuera de contexto. Esto no solamente se puede sostener por la convivencia con términos nativos, que ya cité, sino porque en las lenguas vecinas, tsotsil, tseltal (por lo menos), se usan esos términos también como salutación a personas que no necesariamente tienen lazos consanguíneos. En el español regional se usa también 'hermano' para saludar a una persona con la que no se tiene lazos consanguíneos. Lo interesante del tojolabal probablemente es que se utiliza la palabra de origen castellano únicamente para saludar a personas con las que no se tienen lazos consanguíneos. Se utiliza para abrir una situación de habla no doméstica y esto nos dice mucho del público al que están dirigidos estos textos" (Alejandro Curiel, comunicación personal). 
podría darse, según está lógica, una situación en la que la mujer más anciana de la familia, al abrir su relato en la cocina de su casa, alrededor del fuego y frente a su familia más cercana, se dirija a ellos diciendo "hermanos y hermanas". No obstante, las fórmulas no están incondicionalmente unidas a determinados contextos, sino que son favorecidas y preferidas por éstos (Corrigan, 2009: XV), por lo que no es extraño que ocurra.

Lo que no parece tan descabellado es pensar que el narrador menciona de algún modo a su auditorio y que, si bien aquí lo hace con una fórmula que pertenece más bien a discursos característicos del ámbito público, en el ámbito privado lo haría utilizando otras formas según quién fuera el receptor. No se dispone en este corpus de ninguna versión registrada en el ámbito en el que habitualmente se emiten, pero sí tenemos un ejemplo que podría servir de argumento para tal hipótesis. En una de las estructuras formulísticas de apertura, el narrador cita su fuente directa, su padre, y las palabras con las que éste se dirigió a él cuando le narró el cuento y, en efecto, utilizó el vocativo según nos dice (2):

\begin{tabular}{|l|l|l|}
\hline \multicolumn{2}{|c|}{ El maíz y la hormiga arriera MLC-17 } \\
\hline 1 & Pes ay un cuento; ay un cuento. & Pues hay un cuento; hay un cuento. \\
\hline 2 & $\begin{array}{l}\text { Ja jdejunto cham tati ti wa xjak a } \\
\text { jlo'ila. }\end{array}$ & $\begin{array}{l}\text { De mi difunto padre viene esta } \\
\text { narración. }\end{array}$ \\
\hline 3 & “Pes, hijo, jach' jasta it jun cuento. & $\begin{array}{l}\text { “Pues, hijo, así de esta manera es un } \\
\text { cuento. }\end{array}$ \\
\hline 4 & $\begin{array}{l}\text { Jachb'i cho kab' lo'il sok a b'ajtan } \\
\text { cristiano. }\end{array}$ & $\begin{array}{l}\text { Dicen que así también escuchamos la } \\
\text { narración de los primeros cristianos. }\end{array}$ \\
\hline 5 & $\begin{array}{l}\text { Tonse oj kal awab' jun cuento, jach' } \\
\text { kab', jasta iti”. }\end{array}$ & $\begin{array}{l}\text { Entonces te voy a decir un cuento, } \\
\text { como lo escuché, de esta manera”. }\end{array}$ \\
\hline
\end{tabular}

En los registros de la comunidad Justo Sierra había un auditorio disperso y distante durante el registro, compuesto por vecinos varones de la comunidad, pero el narrador utilizó el vocativo de acuerdo a la persona que lo estaba entrevistando en las dos versiones que él emitió:

\begin{tabular}{|c|l|l|}
\hline \multicolumn{3}{|c|}{ El origen de los animales MLC-1 } \\
\hline 1 & $\begin{array}{l}\text { Pues hermanas, oj jchol awab'yex } \\
\text { t'usan jasta a cuento yalunej kan ja } \\
\text { los antepasado najate 'ili'. }\end{array}$ & $\begin{array}{l}\text { Pues hermana, os voy a contar un poco } \\
\text { cómo es el cuento que dejaron dicho } \\
\text { los antepasados en el pasado aquel. }\end{array}$ \\
\hline 2 & $\begin{array}{l}\text { Jmoj taye' t'um lo'il a ke'n, por } \\
\text { ejemplo, jasta kalata cham kala tat, } \\
\text { cham kala ni'al. }\end{array}$ & $\begin{array}{l}\text { Yo acompañé un poco a contar, por } \\
\text { ejemplo, lo que dijeron mi querido } \\
\text { padre, mi querido suegro, ya difuntos. }\end{array}$ \\
\hline
\end{tabular}


Otro narrador, de la misma comunidad, cuya emisión fue registrada en idénticas circunstancias, también utilizó tan sólo el término 'hermana' pero, a diferencia de todos los casos en los que se usa esta fórmula, no lo hizo en la primera parte de la estructura formulística de apertura, aunque bien es cierto que lo anómalo de ese posicionamiento puede tener que ver con el hecho de que esta fórmula de apertura dividía el relato anterior del siguiente, los cuales fueron emitidos en una sola performance (4):

\begin{tabular}{|l|l|l|}
\hline \multicolumn{3}{|c|}{ La mujer / El maíz y la hormiga arriera / Sombrerón y la mula MLC-21 } \\
\hline 51 & Bueno, ja'xa ja otro porma. & Bueno, en cuanto a eso hay otra forma. \\
\hline 52 & Ja ja'sa yala ja jtati' tukoxa ke'ni. & $\begin{array}{l}\text { Eso es lo que dijo mi padre, que era } \\
\text { mi tocayo. }\end{array}$ \\
\hline 53 & $\begin{array}{l}\text { Hermano, ja mi na' jas stiempo'il, } \\
\text { mi na' jas ora'il... isaber! }\end{array}$ & $\begin{array}{l}\text { Hermana, no se sabe en qué tiempo, } \\
\text { no se sabe a qué hora... ia saber! }\end{array}$ \\
\hline 54 & $\begin{array}{l}\text { Ja'to s-antiguo jtatawe stat a ja } \\
\text { jtataguielo ke'n a ek' el tiempo e'. }\end{array}$ & $\begin{array}{l}\text { Fue en la antigüedad del abuelo del } \\
\text { padre de mi abuelo cuando pasó ese } \\
\text { tiempo. }\end{array}$ \\
\hline
\end{tabular}

En la comunidad San Antonio Tres Cerritos, el narrador emitió la versión en un lugar cercano a su casa y acompañado únicamente de su esposa, su hija y su madre, y abrió la estructura formulística con el vocativo "hermanos", seguido de una elaboración que no hemos encontrado en ningún otro caso de este corpus (5):

\begin{tabular}{|l|l|l|}
\hline \multicolumn{3}{|c|}{ La bolita de pozol MLC-22 } \\
\hline 1 & Pues qué bueno, hermanos. & Pues qué bueno, hermanos. \\
\hline 2 & $\begin{array}{l}\text { Ya que te'yex jmoktik-a, oj jk'uluk } \\
\text { awi'lex contar algo ja la historia b'a } \\
\text { chab' winik scumpare sb'aje'. }\end{array}$ & $\begin{array}{l}\text { Ya que estáis con nosotros, me gustaría } \\
\text { contaros algo de la historia de dos } \\
\text { hombres que se hicieron compadres. }\end{array}$ \\
\hline
\end{tabular}

¿Es acaso este "hermanos" una forma de referirse a la pluralidad de personas que formarán el auditorio futuro cuando vean la película? ¿Están teniendo presente los narradores que utilizan esta forma a ese posible auditorio futuro con el que no tienen lazos consanguíneos y que es indefinidamente plural? Este "hermanos" es mencionado también al abrir la estructura formulística de apertura de una de las tres versiones que emitió el único narrador al que se entrevistó en la comunidad de Lomantán, cuyo registro se hizo en presencia de su esposa, la persona que entrevistaba y dos colaboradores, un hombre y una mujer. En las otras dos versiones, emitidas en este mismo contexto, no utilizó ningún vocativo (6): 


\begin{tabular}{|c|c|c|}
\hline \multicolumn{3}{|c|}{ Sombrerón y la mula MLC-24 } \\
\hline 1 & $\begin{array}{l}\text { Hermanos, pes a ke'ni oj } \mathrm{kal} \\
\text { awab'yex jun cuento. }\end{array}$ & $\begin{array}{l}\text { Hermanos, pues yo voy a deciros un } \\
\text { cuento. }\end{array}$ \\
\hline 2 & Ay ki'oj jun cuento. & Tengo un cuento. \\
\hline 3 & $\begin{array}{l}\text { Pues janek' wa xna'a'i ja yala ja } \\
\text { jme'xeptatagüielotikoni' ja najate'i. }\end{array}$ & $\begin{array}{l}\text { Pues lo que yo sé es lo que dijeron } \\
\text { nuestros abuelos en el pasado. }\end{array}$ \\
\hline 4 & Jun scuento yi'oje'. & Es un cuento que tenían. \\
\hline 5 & $\begin{array}{l}\text { A cuento'i wa xyalawe' que ayb'i jun } \\
\text { winik; ay jun winik. }\end{array}$ & $\begin{array}{l}\text { El cuento que decían era que dicen que } \\
\text { había un hombre; había un hombre. }\end{array}$ \\
\hline
\end{tabular}

En esta estructura formulística, podemos apreciar cómo el narrador, cuando dice "nuestros abuelos" utiliza el plural excluyente -tikon, lo que quiere decir que en ese momento la interlocutora principal no está incluida en ese 'nosotros', que no son de ella esos 'antepasados'. Tenemos aquí la explicitación de la conciencia de la comunidad cultural tojolabal a la que pertenece y su diferencia respecto a alguien no tojolabal. Puede encontrarse este plural en más ocasiones que se señalarán con nota al pie. Eso se refuerza con el hecho de que utilice el término "hermano" para dirigirse a la persona que realiza la entrevista (¿entre otros?) al referirse a su auditorio, pues no tenemos relaciones de consanguineidad. Por otra parte, el término tojolabal que hemos traducido por "nuestros abuelos" está compuesto por las palabras “abuela” (me’xep), en primera posición, y "abuelo" (tataguielo), en segunda. Una traducción muy literal sería, entonces "abuelas-abuelos". En definitiva, para resumir las variaciones de todos los textos respecto de este elemento, el cuadro quedaría como sigue:

\section{Género}

Otro de los elementos que parece obligado en las estructuras formulísticas de apertura es la mención al género con las palabras de origen castellano 'cuento' o 'historia', o con la palabra tojolabal lo'il o la fórmula “chab' palabra” (dos palabras) o con “oxe, chab' palabra” (dos, tres palabras), estas últimas más frecuentes en las estructuras formulísticas de cierre que en las de apertura. No encontramos correlación alguna entre el tipo de relato emitido y la palabra o expresión que utilizan para designarlo. Esto indica que, si de algún modo el género está presente en la mente de los narradores como algo relevante, la estructura formulística no es el lugar en que se hace patente. Otra explicación sería que todos estos textos de tradición oral pertenecieran al mismo género desde el punto de vista de la cultura tojolabal o desde lo que sobre ésta nos dice su idioma, pese a que se pudieran distinguir características propias de las narraciones míticas, los cuentos 


\begin{tabular}{|c|c|c|c|c|c|}
\hline \multirow{2}{*}{ Comunidad } & \multirow{2}{*}{$\begin{array}{c}\text { Nombre del } \\
\text { narrador/a }\end{array}$} & \multirow{2}{*}{ Núm. versión } & \multicolumn{3}{|c|}{ VOCATIVO } \\
\hline & & & HERMANOS Y HERMANAS & HERMANA & HERMANOS \\
\hline \multirow{15}{*}{ 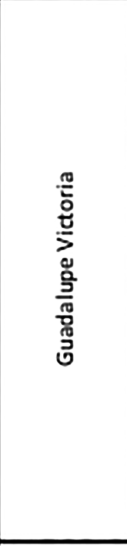 } & \multirow{3}{*}{ Ma. Teresa } & MLC-7 & V & & \\
\hline & & MLC-18 & $\nabla$ & & \\
\hline & & MLC-26 & & & \\
\hline & \multirow{2}{*}{ Mariano } & MLC-9 & & & \\
\hline & & MLC-13 & $\sqrt{2}$ & & \\
\hline & \multirow{3}{*}{ Candelaria } & MLC-20 & & & \\
\hline & & MLC-27 & & & \\
\hline & & MLC-33 & 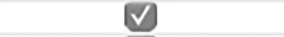 & & \\
\hline & \multirow{2}{*}{ Delina } & MLC-23 & v & & \\
\hline & & MLC-30 & $\sqrt{2}$ & & \\
\hline & Guadalupe & MLC-2 & $\nabla$ & & \\
\hline & Librado & MLC-3 & v & & \\
\hline & Aureliano & MLC-12 & ( & & \\
\hline & Fernando RM & MLC-19 & & & \\
\hline & Adrián PP & MLC-11 & ( & & \\
\hline \multirow{6}{*}{ 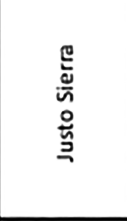 } & Ernesto MM & MLC-21 & & V) & \\
\hline & \multirow{2}{*}{ Gilberto SM } & MLC-5 & & & \\
\hline & & MLC-17 & & & \\
\hline & \multirow{3}{*}{ Carmelino } & $M I C_{-1}$ & & 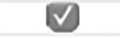 & \\
\hline & & ivile-1 & & & \\
\hline & & MLC-25 & & V & \\
\hline \multirow{10}{*}{ 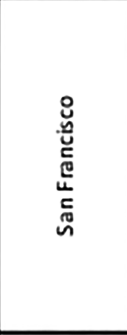 } & \multirow{5}{*}{ Víctor } & MLC-14 & & & \\
\hline & & MLC-28 & & & \\
\hline & & MLC-32 & & & \\
\hline & & MLC-34 & & & \\
\hline & & MLC-35 & & & \\
\hline & \multirow{5}{*}{ Fernando GJ } & MLC-4 & & & \\
\hline & & MLC.6 & & & \\
\hline & & MLC-8 & & & \\
\hline & & MLC-10 & & & \\
\hline & & MLC-15 & & & \\
\hline \multirow{3}{*}{ 只 } & \multirow{3}{*}{ Agustín } & MLC-29 & & & \\
\hline & & MLC-36 & & & \\
\hline & & MLC-37 & & & \\
\hline \multirow{3}{*}{ 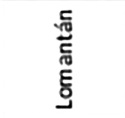 } & \multirow{3}{*}{ Margarito } & MLC-16 & & & \\
\hline & & MLC-24 & & & ( \\
\hline & & MLC-31 & & & \\
\hline 동 & Antonio & MLC-22 & & & v \\
\hline
\end{tabular}


maravillosos o las fábulas de animales con mayor o menor claridad y grado de entrecruzamiento. La explicación más sencilla parece ser que estos tres términos funcionan como sinónimos para denominar un mismo tipo de texto oral desde la perspectiva interna del grupo: teniendo presentes únicamente las 37 versiones de los relatos analizados aquí, no parece existir diferencia alguna entre las palabras 'cuento', 'historia' y lo'il.

De cualquier modo, todos estos términos responden al qué se va a decir, al qué se va a contar. Si tenemos en cuenta que 34 de las 37 versiones advierten de alguna manera el género narrativo que se va a elaborar, no cabe duda de que estamos en lo correcto al decir que éste es un elemento obligatorio en la estructura formulística de apertura y que, normalmente, va después del uso del vocativo con el que se abra dicha estructura.

El término más utilizado es la palabra de origen castellano 'cuento', que podemos encontrar en 21 estructuras formulísticas de apertura de las 34 que utilizan este recurso (7):

\begin{tabular}{|l|l|l|}
\hline \multicolumn{2}{|c|}{ Sombrerón y el tesoro MLC-27 } \\
\hline 1 & $\begin{array}{l}\text { Ja cuento oj jkal awab'ye'xi wajb'i } \\
\text { jun winik. }\end{array}$ & $\begin{array}{l}\text { El cuento que os voy a decir es que } \\
\text { dicen que se fue un hombre. }\end{array}$ \\
\hline
\end{tabular}

En hasta 18 casos, los narradores mencionan el género más de una vez en la estructura formulística de apertura (8):

\begin{tabular}{|l|l|l|}
\hline \multicolumn{2}{|c|}{ El conejo y la figura de cera MLC-33 } \\
\hline 1 & $\begin{array}{l}\text { Hermanos hermanas, oj jkal jun } \\
\text { jcuento ke'. }\end{array}$ & $\begin{array}{l}\text { Hermanos y hermanas, yo voy a decir } \\
\text { un cuento. }\end{array}$ \\
\hline 2 & Ay ki'oj jun jcuento oj kal awab'yex. & Tengo un cuento que os voy a decir. \\
\hline 3 & $\begin{array}{l}\text { Ja' kab'uneji yalujnej kan a cham } \\
\text { jtati y cham jme'xepi'. }\end{array}$ & $\begin{array}{l}\text { Lo que tengo escuchado es lo que } \\
\text { dejaron dicho mi difunto padre y mi } \\
\text { difunta abuela. }\end{array}$ \\
\hline 4 & Yala kab'tikon que ayb'i jun winik. & $\begin{array}{l}\text { Nos dijeron que dicen que había un } \\
\text { hombre. }\end{array}$ \\
\hline
\end{tabular}

Le sigue, en popularidad, el término, también de origen castellano, 'historia', utilizado en nueve ocasiones (9): 


\begin{tabular}{|c|c|c|}
\hline \multicolumn{3}{|c|}{ Sombrerón y la mula MLC-26 } \\
\hline 1 & $\begin{array}{l}\text { Oj kal jun historia yilunej ye'nle } \\
\text { cham jtataguielotikon. }\end{array}$ & $\begin{array}{l}\text { Voy a decir una historia que fue vista } \\
\text { por nuestros* difuntos abuelos. }\end{array}$ \\
\hline 2 & Pues oj kale. & Pues la voy a decir. \\
\hline 3 & $\begin{array}{l}\text { Pues ja najate'i, pes jun winik } \\
\text { chamb'i a xche'umi. }\end{array}$ & $\begin{array}{l}\text { Pues en el pasado, pues había un } \\
\text { hombre al que dicen que se le murió } \\
\text { su esposa. }\end{array}$ \\
\hline
\end{tabular}

* Plural excluyente.

Éste también puede repetirse a lo largo de la estructura formulística, como en el ejemplo de la siguiente versión, emitida por la misma narradora (10):

\begin{tabular}{|c|l|l|}
\hline \multicolumn{3}{|c|}{ El maíz y la hormiga arriera MLC-18 } \\
\hline 1 & $\begin{array}{l}\text { Hermanos, hermanos, pues oj jkal } \\
\text { jun historia jastal yala kan ja cham } \\
\text { jtatagüielo, cham winik, jme'xep. }\end{array}$ & $\begin{array}{l}\text { Hermanas, hermanos, pues voy a decir } \\
\text { una historia, así como la dejó dicha mi } \\
\text { difunto abuelo, hombre difunto, y mi } \\
\text { abuela. }\end{array}$ \\
\hline 2 & $\begin{array}{l}\text { Yala kan jun historia que b'a' jta'tik } \\
\text { ja iximi'. }\end{array}$ & $\begin{array}{l}\text { Dejaron dicha una historia sobre dónde } \\
\text { encontramos el maíz. }\end{array}$ \\
\hline
\end{tabular}

En tan sólo cuatro ocasiones utilizan el término lo’il, que hemos traducido por "narración", y en ninguna de éstas lo utilizan sólo, sino que lo combinan con otra forma de apelar al género, como si no quedara lo suficientemente claro sólo con el primero de los términos. Ejemplo de ello es la versión que sigue (11):

\begin{tabular}{|l|l|l|l|}
\hline \multicolumn{4}{|c|}{ El conejo y el coyote MLC-34 } \\
\hline 1 & $\begin{array}{l}\text { Otro jun yal slo'il: a cuento'il sok a } \\
\text { chich sok a ta ok'ili. }\end{array}$ & $\begin{array}{l}\text { Otra narracioncita: el cuento del } \\
\text { conejo y del coyote. }\end{array}$ \\
\hline
\end{tabular}

En este caso vemos una elaboración breve de la estructura formulística de apertura, pues el narrador que emitió este texto ya había narrado varios previamente de considerable duración, pese a que en ninguno de ellos fue mucho más extenso en sus fórmulas de apertura y cierre. Vemos, además, cómo utiliza el diminutivo yal que modifica a lo'il.

En tan sólo tres casos, puede encontrase, para designar al género, la fórmula que involucra la palabra de origen castellano 'palabra' y que tiene diversas realizaciones. Esta fórmula es más frecuente en las fórmulas de cierre, pero también puede encontrarse en las de apertura, como en el caso que sigue (12): 


\begin{tabular}{|l|l|l|}
\hline \multicolumn{3}{|c|}{ El hombre y el viento MLC-13 } \\
\hline 1 & $\begin{array}{l}\text { Hermanos y hermanas, ja' mismo } \\
\text { palabra chomajkil como jatal yala } \\
\text { jcompa Aureliano. }\end{array}$ & $\begin{array}{l}\text { Hermanos y hermanas, ésta es la misma } \\
\text { palabra otra vez como la que dijo mi } \\
\text { compadre Aureliano.* }\end{array}$ \\
\hline 2 & $\begin{array}{l}\text { La historia como jata k'umani ye'n } \\
\text { cuestion b'a alaj. }\end{array}$ & $\begin{array}{l}\text { Es la historia de la que habló él sobre la } \\
\text { cuestión de la milpa. }\end{array}$ \\
\hline
\end{tabular}

* Se refiere a la versión MLC-12 que fue emitida poco antes por otro narrador vecino de la misma comunidad.

Curiosamente, así como ocurre con lo'il, nunca aparece sola como mención al género, sino que siempre va acompaña de otra forma de designarlo. En el siguiente caso, se encuentra otra de las realizaciones que involucra el mismo término y que también es combinado con la palabra 'historia', de origen castellano, en una estructura formulística muy elaborada (13):

\begin{tabular}{|l|l|l|}
\hline \multicolumn{3}{|c|}{ El origen de los animales MLC-2 } \\
\hline 1 & $\begin{array}{l}\text { Pes ja ke'n, hermanos y hermanas } \\
{[\ldots], \text { oj kal chab' palabra a ke'na }} \\
{[\ldots] .}\end{array}$ & $\begin{array}{l}\text { Pues yo, hermanos y hermanas [...], yo } \\
\text { voy a decir dos palabras [...]. }\end{array}$ \\
\hline 2 & $\begin{array}{l}\text { Y sluwar, oj kal chab' palabra jastal } \\
\text { ja kab'uneja t'usan ja historia yalunej } \\
\text { ja cham, jtataguielotik, najate wa } \\
\text { xyalawe' a historia'i. }\end{array}$ & $\begin{array}{l}\text { Y sobre este asunto, voy a decir dos } \\
\text { palabras tal como tengo escuchada un } \\
\text { poco la historia que han dicho los que } \\
\text { murieron, nuestros abuelos, que en el } \\
\text { pasado decían la historia. }\end{array}$ \\
\hline 3 & $\begin{array}{l}\text { Wa xcha yala'i ja cham jtati y cham } \\
\text { jnani jastal a ti wa ja b'a yab'uneji } \\
\text { jani. }\end{array}$ & $\begin{array}{l}\text { También la decían mi difunto padre y } \\
\text { mi difunta madre tal como la habían } \\
\text { escuchado antes. }\end{array}$ \\
\hline 4 & $\begin{array}{l}\text { Antose ja'b'i ja cristiano ja najate, } \\
\text { wa xyala ye'nle'i que ajyib'i jun } \\
\text { wokol. }\end{array}$ & $\begin{array}{l}\text { Entonces dicen que los cristianos en } \\
\text { el pasado, ellos decían que dicen que } \\
\text { hubo una desgracia. }\end{array}$ \\
\hline
\end{tabular}

Esta estructura de apertura es un ejemplo de cómo la situación contextual influyó en la emisión: en el primer segmento la narradora interrumpe su emisión al recordar que se le debía decir su nombre antes de comenzar; antes de terminar este primer segmento, otra narradora la interrumpe de nuevo para recordarle que también debe decir su comunidad. Sin embargo, vemos que a continuación la narradora vuelve a mencionar, con la misma fórmula ("chab' palabra") el género de su emisión, lo que refuerza nuestra hipótesis de obligatoriedad. En el tercero de los casos en que se utiliza otra realización de esta fórmula, más compleja ("chab', 
oxe palabra"), ésta se combina con lo'il en lugar de con 'historia', como las dos anteriores (14):

\begin{tabular}{|l|l|l|}
\hline \multicolumn{3}{|c|}{ El hombre y el viento MLC-11 } \\
\hline 1 & Pes lek ay, hermanas y hermanos. & Pues está bien, hermanas y hermanos. \\
\hline 2 & $\begin{array}{l}\text { Ay kab'unej jun lo'il b'a ye'na cham } \\
\text { winik jtataguielo jastal yal kan kab'i. }\end{array}$ & $\begin{array}{l}\text { Tengo escuchada una narración de mi } \\
\text { difunto abuelo, así como me la dejó } \\
\text { dicha. }\end{array}$ \\
\hline 3 & $\begin{array}{l}\text { Se'a ta jachuk mi jachukuk, pero } \\
\text { oj kal kan chab', oxe palabra jastal } \\
\text { yalujnej kan kab'i' sok b'a lk'. }\end{array}$ & $\begin{array}{l}\text { Quizá sea así o no sea así, pero voy a } \\
\text { dejar dichas dos, tres palabras como } \\
\text { me las dejó dichas sobre el Viento. }\end{array}$ \\
\hline
\end{tabular}

Como casos muy esporádicos tenemos dos estructuras formulísticas donde el narrador habla de "pensamiento" para anunciar el género que va a emitir (15):

\begin{tabular}{|c|l|l|}
\hline \multicolumn{2}{|c|}{ La bolita de pozol MLC-23 } \\
\hline 1 & $\begin{array}{l}\text { Hermanas y hermanos [...], a ke'na } \\
\text { kab'unej ja iximi'. }\end{array}$ & $\begin{array}{l}\text { Hermanas y hermanos [...],* yo tengo } \\
\text { escuchado lo del maíz. }\end{array}$ \\
\hline 2 & Ja'tani elta pensari, lomni ja jach'uka. & $\begin{array}{l}\text { Ahora que ya salió el pensamiento, de } \\
\text { por sí podría ser así. }\end{array}$ \\
\hline 3 & $\begin{array}{l}\text { Ja' yu, Kajwaltik Diosi ya'a kan a a } \\
\text { jwa'eltiki para que oj ajykotik gusto. }\end{array}$ & $\begin{array}{l}\text { Por eso, Nuestro Señor Dios nos } \\
\text { entregó nuestra comida para que } \\
\text { estuviéramos a gusto. }\end{array}$ \\
\hline * La narradora interrumpe su estructura formulística de apertura para decir sus datos, como se
\end{tabular}
le había pedido.

En este caso, hemos de puntualizar que la narradora enlaza su emisión con aquello que su esposo acababa de decir unos minutos antes sobre el mismo tema, aunque no se trataba del mismo relato. Quizá por esa función (de enlace) la narradora elabora una especie de conclusión en su estructura formulística de apertura. No podemos aventurar ninguna hipótesis, en cambio, al uso del término "pensar", que hemos traducido por 'pensamiento' como designación del género.

Finalmente, tenemos un caso en que este término se combina con 'cultura' en la estructura formulística (16):

\begin{tabular}{|l|l|l|}
\hline \multicolumn{3}{|c|}{ El maíz y la hormiga arriera MLC-19 } \\
\hline 1 & Güieno, ay jun... cultura. & Bueno, hay un... cultura. \\
\hline 2 & Oj kale' jastal ja kila ja najate’. & Voy a decir cómo lo vi en el pasado. \\
\hline
\end{tabular}




\begin{tabular}{|l|l|l|}
\hline 3 & $\begin{array}{l}\text { Pes ja luwara ja jpensari', ti ki'oj } \\
\text { t'usan jk'ulunej grabar tib'a jpensar. }\end{array}$ & $\begin{array}{l}\text { Pues en cuanto a mi pensamiento, } \\
\text { de ahí tengo un poco grabado en mi } \\
\text { pensamiento. }\end{array}$ \\
\hline 4 & $\begin{array}{l}\text { Luwara a ja najate' kila [...] alji } \\
\text { kab'i que ja slwara ja jun patak' ton, } \\
\text { sak'an ja patak' ton jawi'. }\end{array}$ & $\begin{array}{l}\text { En cuanto al pasado, vi [...] me dijeron } \\
\text { sobre un peñasco que estaba vivo el } \\
\text { peñasco aquel. }\end{array}$ \\
\hline
\end{tabular}

El narrador titubeó a la hora de mencionar el género en el primer segmento, se detuvo antes de utilizar este préstamo, "cultura". Su duda quizá también puede manifestarse en el hecho de que en un primer momento dice que hablará de lo que vio; luego lo vuelve a decir (segmento 4), pero reformula, y finalmente dice que recibió esa información de otros, por lo que no fue él testigo directo, además de que habla, en este texto, de una narración situada en el origen de los tiempos. De este modo pasa a adecuarse a la manera formulística habitual. Esto nos podría dar razones para pensar que el uso de 'cultura' como forma de hacer mención al género es completamente excepcional y fruto más de la realización que de una variante personal o de otro tipo. Lo mismo podríamos decir de la utilización del término "porma" (que suponemos es un préstamo de 'forma') que aparece en la estructura formulística de MLC-21, mencionada arriba.

En definitiva, parece que la mención al género es obligada en las estructuras formulísticas de apertura y que sus combinaciones y variantes son ricas. Podríamos resumirlas en el siguiente cuadro en el que cada círculo corresponde a una mención de la palabra con la que se designa el género del texto:

\section{Fuentes del relato}

En 23 estructuras formulísticas de apertura presentes en las versiones del corpus los narradores explicitan de alguna forma que no fueron testigos de los hechos que narran, esto es, que les han llegado por medio de una fuente indirecta. En hasta 14 ocasiones mencionan explícitamente su fuente (17):

\begin{tabular}{|l|l|l|}
\hline \multicolumn{3}{|c|}{ El maíz y la hormiga arriera MLC-20 } \\
\hline 1 & $\begin{array}{l}\text { Ja historia oj jkale pes como jastal } \\
\text { kab'unej ja yala jcham jtataguielo ja } \\
\text { najate'i. }\end{array}$ & $\begin{array}{l}\text { La historia que voy a decir pues es así } \\
\text { como tengo escuchada que la dijo mi } \\
\text { difunto abuelo en el pasado. }\end{array}$ \\
\hline
\end{tabular}

Si el narrador escuchó la historia de varias fuentes, las menciona como ocurre en el siguiente caso (18): 


\begin{tabular}{|c|c|c|c|c|c|c|c|c|c|}
\hline \multirow{2}{*}{ Comunidad } & \multirow{2}{*}{ Narrador/a } & \multirow{2}{*}{$\begin{array}{l}\text { Núm. } \\
\text { Versión }\end{array}$} & \multicolumn{7}{|c|}{ GÉNERO } \\
\hline & & & CUENTO & HISTORIA & LO'IL & PALABRA & PENSAMIENTO & CULTURA & PORMA \\
\hline \multirow{15}{*}{ 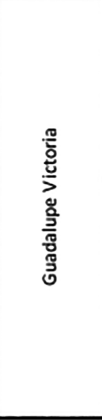 } & \multirow{3}{*}{ Ma. Teresa } & MLC-7 & & & & & & & \\
\hline & & MLC-18 & & & & & & & \\
\hline & & MLC-26 & & & & & & & \\
\hline & \multirow{2}{*}{ Mariano } & MLC-9 & & & & & & & \\
\hline & & MLC-13 & & & & & & & \\
\hline & \multirow{3}{*}{ Candelaria } & MLC-20 & & & & & & & \\
\hline & & MLC-27 & & & & & & & \\
\hline & & MLC-33 & & & & & & & \\
\hline & \multirow{2}{*}{ Delina } & MLC-23 & & & & & & & \\
\hline & & MLC-30 & & & & & & & \\
\hline & Guadalupe & MLC-2 & & & & & & & \\
\hline & Librado & MLC-3 & & & & & & & \\
\hline & Aureliano & MLC-12 & & & & & & & \\
\hline & Fernando RM & MLC-19 & & & & & & 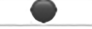 & \\
\hline & Adrián PP & MLC-11 & & & & 0 & & & \\
\hline \multirow{5}{*}{ 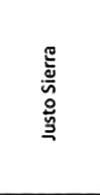 } & Ernesto $\mathrm{MM}$ & MLC-21 & & & & & & & \\
\hline & \multirow{2}{*}{ Gilberto SM } & MLC-5 & & & & & & & \\
\hline & & MLC-17 & & & & & & & \\
\hline & \multirow{2}{*}{ Carmelino } & MLC-1 & & & & & & & \\
\hline & & MLC-25 & & & & & & & \\
\hline \multirow{10}{*}{ 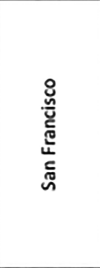 } & \multirow{5}{*}{ Victor } & MLC-14 & & & & & & & \\
\hline & & MLC-28 & & & & & & & \\
\hline & & MLC-32 & & & & & & & \\
\hline & & MLC-34 & & & 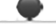 & & & & \\
\hline & & MLC-35 & & & & & & & \\
\hline & \multirow{5}{*}{ Fernando GJ } & MLC-4 & & & & & & & \\
\hline & & MLC. 6 & & & & & & & \\
\hline & & MLC-8 & & & & & & & \\
\hline & & MLC-10 & & & & & & & \\
\hline & & MLC-15 & & & & & & & \\
\hline \multirow{3}{*}{$\stackrel{\varrho}{\stackrel{\Xi}{\Xi}}$} & \multirow{3}{*}{ Agustin } & MLC-29 & & & & & & & \\
\hline & & MLC-36 & & & 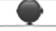 & & & & \\
\hline & & MLC-37 & & & & & & & \\
\hline \multirow{3}{*}{ 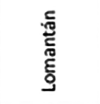 } & \multirow{3}{*}{ Margarito } & MLC-16 & & & & & & & \\
\hline & & MLC-24 & & & & & & & \\
\hline & & MLC-31 & & & & & & & \\
\hline 怘 & Antonio & MLC-22 & & & & & & & \\
\hline
\end{tabular}

\begin{tabular}{|l|l|l|}
\hline \multicolumn{3}{|c|}{ Los hermanos y la miel MLC-7 } \\
\hline 1 & $\begin{array}{l}\text { Hermanos y hermanas, oj kal jun } \\
\text { historia como jastal yalunej kan a } \\
\text { cham jtataguielo, chamel winik jtat. }\end{array}$ & $\begin{array}{l}\text { Hermanos y hermanas, voy a decir una } \\
\text { historia, así como me la dejaron dicha } \\
\text { mi difunto abuelo y el hombre difunto, } \\
\text { mi padre. }\end{array}$ \\
\hline 2 & $\begin{array}{l}\text { Oj kal jun historia como jastal yala } \\
\text { kan kab'tikoni. }\end{array}$ & $\begin{array}{l}\text { Voy a decir una historia, así como nos } \\
\text { la dejaron dicha. }\end{array}$ \\
\hline 3 & Pues ti oj kal a giiego'i. & Pues de ahí la voy a decir ahora. \\
\hline
\end{tabular}


En el ejemplo que sigue, la narradora hace un recorrido por los familiares que dijeron el relato que va a contar, dando cuenta de cómo funciona la transmisión de la narrativa de tradición oral (19):

\begin{tabular}{|l|l|l|}
\hline \multicolumn{3}{|c|}{ Juan Haragán y el zopilote MLC-30 } \\
\hline 1 & $\begin{array}{l}\text { Hermano y hermana, pes ja ke'ni } \\
\text { kab'unej jun historia. }\end{array}$ & $\begin{array}{l}\text { Hermanos y hermanas, pues yo tengo } \\
\text { escuchada una historia. }\end{array}$ \\
\hline 2 & $\begin{array}{l}\text { Y a kab'unej ke'n yalujnej kan cham } \\
\text { me'jun jme'xepi', jtataweli', pe ja' alji } \\
\text { kan yab' a dejunto jtati, ja'xa jtati', } \\
\text { ye'nxa cho yal kab'tikon. }\end{array}$ & $\begin{array}{l}\text { Y yo tengo escuchado lo que me dejó } \\
\text { dicho mi difunta abuela, mi abuelo, } \\
\text { pero también se lo dijeron a mi difunto } \\
\text { padre, mi padre, él también la contó. }\end{array}$ \\
\hline
\end{tabular}

En nueve estructuras formulísticas de apertura el narrador menciona, no la fuente directa (o no sólo), sino lo que aquí hemos llamado la "fuente originaria", esto es, los antepasados que, en algunas ocasiones, contaron y, en otras, vieron la historia que se narra. Por medio de esta mención, los narradores expresan la conciencia de la naturaleza de la transmisión oral cuya línea de vida se extiende desde el presente hasta el origen de los tiempos.

El hecho de que este relato se sitúe en el tiempo de los antepasados no es cualquier cosa. Algo que sucedió o que se contó en el origen no es un hecho arbitrario, sino configurador, que por ello habrá de tener cierta sacralidad y que circunda determinada comunidad cultural al abrigo de esa tradición. El siguiente ejemplo nos muestra cómo el narrador distingue los dos tipos de fuente de información, la directa y la originaria (20):

\begin{tabular}{|l|l|l|}
\hline \multicolumn{3}{|c|}{ El maíz y la hormiga arriera MLC-17 } \\
\hline 1 & Pes ay un cuento; ay un cuento. & Pues hay un cuento; hay un cuento. \\
\hline 2 & $\begin{array}{l}\text { Ja jdejunto cham tati ti wa xjak a } \\
\text { jlo'ila. }\end{array}$ & $\begin{array}{l}\text { De mi difunto padre viene esta } \\
\text { narración. }\end{array}$ \\
\hline 3 & “Pes, hijo, jach' jasta it jun cuento. & $\begin{array}{l}\text { "Pues, hijo, así de esta manera es un } \\
\text { cuento. }\end{array}$ \\
\hline 4 & $\begin{array}{l}\text { Jachb'i cho kab' lo'il sok a b'ajtan } \\
\text { cristiano. }\end{array}$ & $\begin{array}{l}\text { Dicen que así también escuchamos la } \\
\text { narración de los primeros cristianos. }\end{array}$ \\
\hline 5 & $\begin{array}{l}\text { Tonse oj kal awab' jun cuento, jach', } \\
\text { kab', jasta iti”. }\end{array}$ & $\begin{array}{l}\text { Entonces te voy a decir un cuento, } \\
\text { como lo escuché, de esta manera”. }\end{array}$ \\
\hline
\end{tabular}

Cuando mencionan esta fuente originaria, los narradores aluden a ella de diferentes formas según el corpus con el que aquí trabajamos: "cham jtatagüelotikon", 'nuestros difuntos abuelos', con plural excluyente (MLC-26); "ja cham, jtatagüe- 
lotik”, 'los que murieron, nuestros abuelos', con plural incluyente (MLC-2); "ja jnajtati", 'nuestras madres-padres', con plural incluyente (MLC-21); "ja los antiguo", 'los antiguos' MLC-21; "a b'ajtan cristiano, ja yora ajyitik [...]”, 'los primeros cristianos, cuando estuvimos [...]', con plural incluyente (MLC-5); "Ios antepasado”, 'los antepasados' (MLC-1); “ja jme'xeptatagüelotikon”, 'nuestros abuelos', con plural excluyente (MLC-16). Pero, de cualquier modo, la idea general es que la fuente originaria son los antepasados que, en algunos casos son, explícitamente, los antepasados tojolabales y no, por decirlo así, los de la humanidad, cosa que ponen de manifiesto con el plural -tikon, que no incluye a la persona que realizó la entrevista, mientras que, en otras ocasiones, sí lo hacen.

Aunque en el ejemplo anteriormente citado el narrador menciona la fuente directa y la fuente originaria, tenemos también casos en los que tan sólo se alude a esta segunda, como el caso que sigue (21):

\begin{tabular}{|l|l|l|}
\hline \multicolumn{4}{|c|}{ La mujer / El maíz y la hormiga arriera / Sombrerón y la mula MLC-21 } \\
\hline 1 & $\begin{array}{l}\text { Pues ja ek' el el tiempo ja jnajtati' } \\
\text { yila jan a cosa b'a leki, yila jan ja } \\
\text { b'a sk'ulan chingar ja ajyi jan ja los } \\
\text { antiguo. }\end{array}$ & $\begin{array}{l}\text { Pues cuando pasó el tiempo de } \\
\text { nuestras madres-padres vieron cosas } \\
\text { bien, vieron cómo nos chingaron los } \\
\text { antiguos. }\end{array}$ \\
\hline 2 & $\begin{array}{l}\text { Saber jas hora mi nab'en jas } \\
\text { stiempo'il pero yujxta yala kan a } \\
\text { jnajtik que ja cuento iti. }\end{array}$ & $\begin{array}{l}\text { A saber a qué hora ni en qué tiempo } \\
\text { pero me lo dejaron dicho en nuestra } \\
\text { casa este cuento. }\end{array}$ \\
\hline
\end{tabular}

Como vemos, en este caso nos dice quiénes fueron los testigos directos de los hechos. En otras ocasiones, la fuente originaria no es testigo de los hechos, sino sólo transmisor (22):

\begin{tabular}{|c|l|l|}
\hline \multicolumn{3}{|c|}{ Sombrerón y la mula MLC-25 } \\
\hline 1 & $\begin{array}{l}\text { Bueno, hermana, oj jchol awab' jun } \\
\text { cuento.* }\end{array}$ & $\begin{array}{l}\text { Bueno, hermana, os voy a narrar un } \\
\text { cuento. }\end{array}$ \\
\hline 2 & $\begin{array}{l}\text { Oj kal awab'yex jun cuento jastal a } \\
\text { cuento b'a Diablo y mula. }\end{array}$ & $\begin{array}{l}\text { Os voy a decir un cuento que es así: el } \\
\text { cuento del Diablo y la mula. }\end{array}$ \\
\hline 3 & $\begin{array}{l}\text { Ja tiwi yala kan a los antepasados } \\
\text { ja' sb'ej a ja Diablo sok } a \text { mula'i. }\end{array}$ & $\begin{array}{l}\text { Esto es lo que dejaron dicho los } \\
\text { antepasados sobre el tema del Diablo } \\
\text { y la mula. }\end{array}$ \\
\hline
\end{tabular}

* En este momento el narrador interrumpe su fórmula de inicio para decir sus datos personales.

En cuatro estructuras formulísticas de apertura en las que el narrador o narradora no menciona ni la fuente directa ni la indirecta, sí explicita, en cambio, que el relato que va a narrar lo escuchó aunque no dice de quién, o lo que se denomina aquí "fuente indefinida" (23): 


\begin{tabular}{|l|l|l|}
\hline \multicolumn{2}{|c|}{ La tigresa y el pueblo sin agua MLC-36 } \\
\hline 1 & Oj kal jun cuento. & Voy a decir un cuento. \\
\hline 2 & Ja ke'ni kab' jun lo'il alji kab'i. & $\begin{array}{l}\text { Yo escuché una narración que me } \\
\text { dijeron. }\end{array}$ \\
\hline
\end{tabular}

De todos los casos que se analizan en este corpus, existen dos en los que el narrador dice que va a contar lo que vio, esto es, que fue testigo de los hechos. En una de ellas, se desdice, como vemos (24):

\begin{tabular}{|l|l|l|}
\hline \multicolumn{3}{|c|}{ Los hermanos Rayo MLC-9 } \\
\hline 1 & $\begin{array}{l}\text { Oj ka' ek' awi'lex como jasuk'a kila } \\
\text { jani. }\end{array}$ & Os voy a pasar lo que vi. \\
\hline 2 & Bueno, mi kila, jun historia, pues. & Bueno, no lo vi, es una historia, pues. \\
\hline 3 & $\begin{array}{l}\text { Oj kal awab'yex ja ke'n jastal como } \\
\text { wan yaljel como ese del Chawuki': } \\
\text { jun historia kab'unej a ke'n. }\end{array}$ & $\begin{array}{l}\text { Yo voy a deciros lo que estuvieron } \\
\text { diciendo de cómo es eso del Rayo: una } \\
\text { historia que yo tengo escuchada. }\end{array}$ \\
\hline 4 & $\begin{array}{l}\text { Kab' jun historia ke'n como mucho } \\
\text { ante que jun winik ay yi'oj chab' } \\
\text { yuntikil y ja chab' yuntikil jawi' wa } \\
\text { sjeka loxinel. }\end{array}$ & $\begin{array}{l}\text { Yo escuché una historia de que mucho } \\
\text { antes un hombre tenía dos hijos y a los } \\
\text { dos hijos aquellos los envió a rozar. }\end{array}$ \\
\hline
\end{tabular}

Cuando el narrador se desdice de haber afirmado que fue testigo ocular de lo que va a contar, explica también que es una "historia", esto es, que el género así designado ya debe implicar de alguna forma que el narrador no es fuente directa del relato. La estructura formulística donde el narrador se dice testigo ocular de los hechos es la MLC-19, mencionada antes, y que tiene otros elementos que no encontramos en ningún otro caso, por lo que no se puede extraer de ella la conclusión de que exista ningún subtipo o modelo.

En definitiva, podemos afirmar que en las estructuras formulísticas de apertura es relevante o necesaria la explicitación de que el relato que se narra proviene de una fuente distinta al propio narrador, que no fue testigo de los hechos. Relevante también parece ser la mención de la fuente directa de éste, que en casi todos los casos es un familiar. La historia cobra cierto tono solemne cuando se menciona que proviene de los antepasados y, quizá también, cierto valor sagrado y carácter fehaciente. El hecho de que los antepasados sean la fuente originaria le da autoridad al narrador que reproduce el relato importante. Se pueden resumir los resultados de este análisis en el siguiente cuadro, en el que se señala con un símbolo el tipo de fuente a la que se alude en cada versión: 


\begin{tabular}{|c|c|c|c|c|c|c|c|}
\hline Comunidad & Narrador/a & $\begin{array}{l}\text { Núm. } \\
\text { Versión }\end{array}$ & Fuente directa & Fuente originaria & Testigos & Fuente indefinida & Excepciones \\
\hline \multirow{15}{*}{ 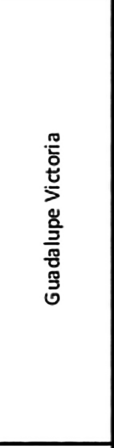 } & \multirow{3}{*}{ Ma. Teresa } & MLC-7 & & & & & \\
\hline & & MLC-18 & & & & & \\
\hline & & MLC-26 & & & & & \\
\hline & \multirow{2}{*}{ Mariano } & MLC-9 & & & & & \\
\hline & & MLC-13 & & & & & \\
\hline & \multirow{3}{*}{ Candelaria } & MLC-20 & & & & & \\
\hline & & MLC-27 & & & & & \\
\hline & & MLC-33 & & & & & \\
\hline & \multirow{2}{*}{ Delina } & MLC-23 & & & & & \\
\hline & & MLC-30 & & & & & \\
\hline & Guadalupe & MLC-2 & & & & & \\
\hline & Librado & MLC-3 & & & & & \\
\hline & Aureliano & MLC-12 & & & & & \\
\hline & Fernando RM & MLC-19 & & & & & \\
\hline & Adrián PP & MLC-11 & & & & & \\
\hline \multirow{5}{*}{ 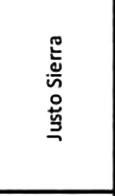 } & Ernesto MM & MLC-21 & & & & & \\
\hline & \multirow{2}{*}{ Gilberto SM } & MLC-5 & & & & & \\
\hline & & MLC-17 & & & & & \\
\hline & \multirow{2}{*}{ Carmelino } & MLC-1 & & & & & \\
\hline & & MLC-25 & & & & & \\
\hline \multirow{10}{*}{ 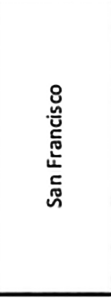 } & \multirow{5}{*}{ Víctor } & MLC-14 & & & & & \\
\hline & & MLC-28 & & & & & \\
\hline & & MLC-32 & & & & & \\
\hline & & MLC-34 & & & & & \\
\hline & & MLC-35 & & & & & \\
\hline & \multirow{5}{*}{ Fernando GJ } & MLC-4 & & & & & \\
\hline & & MLC-6 & & & & & \\
\hline & & MLC-8 & & & & & \\
\hline & & MLC-10 & & & & & \\
\hline & & MLC-15 & & & & & \\
\hline \multirow{3}{*}{ 을 } & \multirow{3}{*}{ Agustín } & MLC-29 & & & & & \\
\hline & & MLC-36 & & & & & \\
\hline & & MLC-37 & & & & & \\
\hline \multirow{3}{*}{ 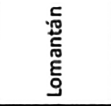 } & \multirow{3}{*}{ Margarito } & MLC-16 & & & & & \\
\hline & & MLC-24 & & & & & \\
\hline & & MLC-31 & & & & & \\
\hline 규 $\frac{0}{\frac{1}{2}}$ & Antonio & MLC-22 & & & & & \\
\hline
\end{tabular}

Es esperable que, si los hechos que nos narran no han sido vistos por los propios ojos de los narradores que los reproducen, éstos mencionen la fidelidad de su reproducción, el intento de ajustarse a lo que ellos escucharon. En todas las versiones en que hacen esto afirman que van a decir el relato tal y como lo escucharon (“jastal yal kan kab'i” o 'así como me la dejó dicha'), menos en una versión, MLC-11, arriba mencionada, donde el propio narrador muestra la duda de la fidelidad de su reproducción: "Se'a ta jachuk mi jachukuk, pero oj kal kan chab', 
oxe palabra jastal yalujnej kan kab'i' sok b’a Ik", que quiere decir "Quizá fue así o no fue así, pero voy a dejar dichas dos, tres palabras como me las dejó dichas sobre el Viento".

\section{Temporalidad}

Si bien esta distancia que existe entre ellos y los hechos alivia a los narradores del compromiso acerca de su veracidad, a la vez, ésta se ve reforzada por la sacralidad de un relato ancestral. La mención a los antepasados va estrechamente unida a la temporalidad, pues la antiguiedad de aquellos implica la antigüedad del relato, lo cual, en toda sociedad tradicional, otorga valor a aquello de lo que se trate: la costumbre o "el costumbre" es a veces la única respuesta que nos dan a los antropólogos cuando preguntamos sobre el porqué de determinada práctica, pues el hecho de que sea costumbre es fuerza suficiente y motor incuestionado para reproducirla y perpetuarla. La antigüedad, por tanto, es fuente de valor. En ocasiones, no contentos con la temporalidad ya implicada en la mención a una fuente originaria como los antepasados, los narradores y narradoras hacen mención explícita al tiempo remoto en que se contaron o en que sucedieron los hechos, o también (en menos ocasiones) en que les fueron transmitidos a ellos.

En hasta 16 estructuras formulísticas de apertura los narradores hacen alguna mención a estas tres variantes de la temporalidad. Lo más frecuente es que mencionen el tiempo en que sucedieron los hechos que van a relatar. A veces, éste elemento es el único reconocible de las estructuras formulísticas de apertura, como es el caso que sigue (25):

\begin{tabular}{|l|l|l|}
\hline \multicolumn{3}{|c|}{ Los hermanos y la miel MLC-8 } \\
\hline 1 & $\begin{array}{l}\text { Ja najate'i ay jun tan jach sniwanil } \\
\text { tan te'i. }\end{array}$ & $\begin{array}{l}\text { En el pasado había un árbol así de } \\
\text { grande.* }\end{array}$ \\
\hline
\end{tabular}

En otras ocasiones, este elemento se combina con otros ya mencionados, como en este caso, donde se hace alusión al género y a la fuente remota (26): 


\begin{tabular}{|l|l|l|}
\hline \multicolumn{3}{|c|}{ El maíz y la hormiga arriera MLC-16 } \\
\hline 1 & Oj cha kal otro cuento. & Voy a decir otro cuento. \\
\hline 2 & $\begin{array}{l}\text { Alji kab' kala me'xeptatagüielotikoni' } \\
\text { yalawe' jastal a cuento iti'. }\end{array}$ & $\begin{array}{l}\text { Me fue dicho por nuestros* abuelos** } \\
\text { que dijeron así este cuento. }\end{array}$ \\
\hline 3 & $\begin{array}{l}\text { A cuento iti' ja najate'i, pues } \\
\text { el tiempo jastal tan ja svida ja } \\
\text { jme'xeptataguielotikon jan ajyi'. }\end{array}$ & $\begin{array}{l}\text { Este cuento es del pasado, del tiempo } \\
\text { de la vida de nuestros*** abuelos que } \\
\text { estuvieron. }\end{array}$ \\
\hline 4 & $\begin{array}{l}\text { Ja yora mito ayuk ja iximi'; mito ayuk } \\
\text { a iximi; creo que mito xya'a sb'aj } \\
\text { Jnantik Ixima. }\end{array}$ & $\begin{array}{l}\text { Era la hora en que todavía no había } \\
\text { maíz; todavía no había maíz; creo que } \\
\text { todavía no se entregaba Nuestra**** } \\
\text { Madre Maíz. }\end{array}$ \\
& $\begin{array}{l}* \text { Plural excluyente. } \\
* * \text { Literalmente, 'nuestros-abuelas-abuelos'. } \\
* * * \text { Plural excluyente. } \\
* * * * \text { En este caso, el narrador utiliza el plural incluyente -tik. }\end{array}$
\end{tabular}

Puede observarse que el narrador sitúa su relato en un tiempo "otro" en que el mundo no era tal y como lo conocemos ahora, sino que era el tiempo en el que éste se configuraba y cuyos cambios determinaron el mundo hasta hoy. Este otro tiempo es propio de las narraciones míticas que tienen una función etiológica, entre otras, mediante la cual explican las características del mundo. Tenemos otros ejemplos, donde la expresión de la temporalidad se da también con detalle, como el que sigue (27):

\begin{tabular}{|c|l|l|}
\hline \multicolumn{3}{|c|}{ El maíz y la hormiga arriera MLC-14 } \\
\hline 1 & $\begin{array}{l}\text { Ojb'i kaltik otro jastal ta'x a ixim } \\
\text { ja yora ja cuando chiknaji jastali, } \\
\text { porque mi ma' wa sna'a hace saber: } \\
\text { jitsanxa jab'il, jitsan jab'il, mixa } \\
\text { kechanuk cien y doscientos ni mil. }\end{array}$ & $\begin{array}{l}\text { Dicen que vamos a decir otro [cuento] } \\
\text { de cómo se encontró el maíz a la hora } \\
\text { en que se descubrió porque nadie sabe } \\
\text { hace cuánto: a saber, ya muchos años, } \\
\text { muchos años, ya no solamente cien y } \\
\text { doscientos ni mil. }\end{array}$ \\
\hline 2 & Jun tiempo il, a jun yal chan [...]. & En un tiempo allá, un pajarito [...]. \\
\hline
\end{tabular}

En cuatro de las 16 estructuras formulísticas de apertura se menciona, no el tiempo en que sucedieron los hechos que se van a narrar, sino el tiempo remoto en que se narraban. De este modo se hace hincapié en la antiguiedad del relato en tanto que relato. En una ocasión, incluso, dicen que se trata del primer relato (28): 


\begin{tabular}{|l|l|l|}
\hline \multicolumn{3}{|c|}{ Los hermanos Rayo MLC-10 } \\
\hline 1 & Oj kal a güego a cuento'a. & Voy a decir ahora un cuento. \\
\hline 2 & $\begin{array}{l}\text { Oj cha kal a cuento, ja primero, } \\
\text { primera cuento jasta ay a jaw. }\end{array}$ & $\begin{array}{l}\text { Voy a decir también* el cuento, el } \\
\text { primero, el primer cuento de cómo era } \\
\text { aquello. }\end{array}$ \\
\hline
\end{tabular}

*Este transmisor ya había narrado antes.

En dos estructuras formulísticas que ya se han mencionado, los narradores dicen que el relato les fue contado "ja najate", 'en el pasado' (MLC-3 y MLC-20). En definitiva, se podría decir que la antiguiedad del relato parece ser relevante y otorga (o refuerza) al acto narrativo como un acto que toca con el origen y, por ello, está dotado de cierta sacralidad. Se podrían resumir las menciones a la temporalidad en el siguiente cuadro, en el que cada símbolo representa el modo en que se expresa la temporalidad (cuando se expresa) en cada versión:

\begin{tabular}{|c|c|c|c|c|c|}
\hline \multirow{2}{*}{ Comunidad } & \multirow{2}{*}{ Narrador/a } & \multirow{2}{*}{$\begin{array}{l}\text { Núm. } \\
\text { Versión }\end{array}$} & \multicolumn{3}{|c|}{ Temporalidad } \\
\hline & & & En que sucedió & En que se narró en el origen & En que lo escuchó el narrador \\
\hline \multirow{15}{*}{ 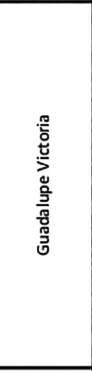 } & \multirow{3}{*}{ Ma. Teresa } & MLC-7 & & & \\
\hline & & MLC-18 & & & \\
\hline & & MLC-26 & & & \\
\hline & \multirow{2}{*}{ Mariano } & MLC-9 & $\Delta$ & & \\
\hline & & MLC-13 & & & \\
\hline & \multirow{3}{*}{ Candelaria } & MLC-20 & & & $\Delta$ \\
\hline & & MLC-27 & & & \\
\hline & & MLC-33 & & & \\
\hline & \multirow{2}{*}{ Delina } & MLC-23 & & & \\
\hline & & MLC-30 & & & \\
\hline & Guadalupe & MLC-2 & & $\Delta$ & \\
\hline & Librado & MLC-3 & & & $\Delta$ \\
\hline & Aureliano & MLC-12 & & & \\
\hline & Fernando RM & MLC-19 & & & \\
\hline & Adrián PP & MLC-11 & & & \\
\hline \multirow{7}{*}{ 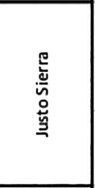 } & \multirow{2}{*}{ Ernesto MM } & \multirow{2}{*}{ MLC-21 } & $\Delta$ & & \\
\hline & & & $\Delta$ & & \\
\hline & \multirow{2}{*}{ Gilberto SM } & MLC-5 & $\Delta$ & & \\
\hline & & MLC-17 & & & \\
\hline & \multirow{3}{*}{ Carmelino } & MLC-1 & & $\Delta$ & \\
\hline & & & & & \\
\hline & & MLC-25 & & & \\
\hline \multirow{10}{*}{ 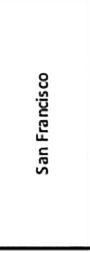 } & \multirow{5}{*}{ Victor } & MLC-14 & $\Delta$ & & \\
\hline & & MLC-28 & & & \\
\hline & & MLC-32 & & & \\
\hline & & MLC-34 & & & \\
\hline & & MLC-35 & $\Delta$ & & \\
\hline & \multirow{5}{*}{ Fernando GJ } & MLC-4 & & & \\
\hline & & MLC. 6 & $\Delta$ & & \\
\hline & & MLC-8 & $\Delta$ & & \\
\hline & & MLC-10 & & $\Delta$ & \\
\hline & & MLC-15 & $\boldsymbol{\Delta}$ & & \\
\hline \multirow{3}{*}{ 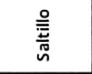 } & \multirow{3}{*}{ Agustin } & MLC-29 & & & \\
\hline & & MLC-36 & & & \\
\hline & & MLC-37 & & & \\
\hline \multirow{3}{*}{ 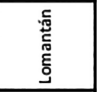 } & \multirow{3}{*}{ Margarito } & MLC-16 & $\Delta$ & & \\
\hline & & MLC-24 & & $\Delta$ & \\
\hline & & MLC-31 & & & \\
\hline 号 & Antonio & MLC-22 & & & \\
\hline
\end{tabular}


Hay tan sólo un caso en todo el corpus en el que el narrador abre su emisión haciendo referencia al lugar concreto donde sucedieron los hechos. Este recurso refuerza directamente el valor de la verdad de los acontecimientos que se narran. Se trata de un recurso muy habitual en el género de la leyenda que, sin embargo, no encuentra en este corpus de textos ningún relato que pudiera adscribírsele. La mención al lugar concreto también acerca temporalmente lo relatado al auditorio, y deja de situarlos en ese "otro tiempo" en el que el mundo está configurándose para situarlos en el tiempo de los hombres. En el caso que se menciona aquí, el narrador apuntaba con su mano a la orientación exacta del municipio al que se refería, como quien dice "aquí al lado". Sin embargo, los hechos que cuenta no son en algún caso cotidianos, sino del todo extraordinarios: narran la captura por parte de unos hombres de otros hombres-viento, que perjudicaban las cosechas (29):

\begin{tabular}{|c|c|c|}
\hline \multicolumn{3}{|c|}{ El hombre Viento MLC-12 } \\
\hline 1 & $\begin{array}{l}\text { Bueno, hermanos y hermanas, } \\
\text { pues ay ki'oj otro cuento que } \\
\text { jasuk'a alub'al kab'i. }\end{array}$ & $\begin{array}{l}\text { Bueno, hermanos y hermanas, pues } \\
\text { tengo* otro cuento que me han dicho. }\end{array}$ \\
\hline 2 & $\begin{array}{l}\text { Mas que alji kab'i ja machuk'a ek' } \\
\text { paxta. }\end{array}$ & $\begin{array}{l}\text { Sobre todo porque me lo dijeron los } \\
\text { que ya han muerto. }\end{array}$ \\
\hline 3 & $\begin{array}{l}\text { Ajyi jun perjuicio que comon } \\
\text { jumasa lado municipio Margarita. }\end{array}$ & $\begin{array}{l}\text { Hubo un perjuicio en las comunidades } \\
\text { del lado del municipio de Margaritas.** }\end{array}$ \\
\hline
\end{tabular}

\section{Conclusiones}

Los estudios realizados hasta ahora sobre la tradición literaria maya nos muestran que esta antigua tradición tiene algunos aspectos específicos que permanecen a lo largo del tiempo, como el paralelismo, y que son característicos aún hoy de diferentes eventos de habla entre los que se encuentra la narrativa (Barrett: 2017). En este trabajo hemos querido añadir a tales estudios los resultados de un análisis sobre un recurso muy específico que hemos denominado "estructuras formulísticas de apertura”. Desde un punto de vista linguiístico, éstas forman parte de lo que Pawley denomina "actos de habla”, pues su función va más allá de la mera denotación o predicación, se realizan mediante una expresión convencional y están ligadas a un contexto particular (Pawley, 2009: 6). Estas fórmulas constituyen auténticas instituciones sociales que determinan lo que se puede decir (significado), el modo en que se puede decir de una forma idiomática (forma), la 
razón por la que se dice (función) y cuándo se dice (contexto) (Pawley, 2009: 8). Con excepción de una de las partes más importantes de este recurso, el contexto, por razón del modo de registro (preparado) en que se realizaron los registros de los textos aquí analizados, hemos intentado en este trabajo recorrer cada una de las caras que Pawley menciona, y hemos llegado a las siguientes conclusiones.

La narrativa de tradición oral tojolabal obliga ser precedida por estructuras formulísticas de apertura, complejas, que cuentan con elementos más o menos obligados que se combinan de diferente forma. El vocativo, el género, la fuente y la temporalidad son los más frecuentes de entre ellos. Mediante estas estructuras formulísticas, los narradores enmarcan el discurso oral que van a emitir y lo separan del resto de emisiones orales a la vez que anuncian el monopolio del uso de la palabra. Tienen, por tanto, una función de nexo y a la vez de frontera entre la situación contextual y la ficción del relato. En los textos aquí analizados no encontramos un cuento-marco que unifique varios de ellos dentro de una ficción, al modo en que Bonnie D. Irwin (1995) apunta, sino que cada cuento se enmarca de forma aislada.

El género oral que enmarcan con dichas estructuras es siempre una elaboración artística tradicional, con independencia de qué diferencias o subgéneros existan dentro de esta gran clasificación. En términos de estructuras formulísticas de apertura no parece ser relevante la diferenciación de tales subgéneros, si es que lo es en otros ámbitos. También mediante las estructuras formulísticas de apertura, los narradores hablan del propio mensaje como un mensaje que pertenece, no a su talento creativo personal, sino a la comunidad cultural, sirviendo así de refuerzo de la identidad colectiva. Ofrecen información de su fuente del relato distanciándose así de los hechos que reproducen y legitimándolos como palabras en cierto modo sagradas o, al menos, determinantes por su pertenencia a "otro" tiempo o al tiempo pasado, siempre importante y configurador del mundo actual. Según Briggs y Bauman (1992) dicha referencia intertextual sería determinante a la hora de pensar el género al que pertenecen los textos y vendría marcada, en este caso, por una minimización de la distancia intertextual entre la elaboración particular de cada narrador y sus precedentes genéricos con la finalidad, en términos de poder, de dotar de autoridad a sus palabras.

\section{Bibliografía}

Bauman, Richard

1992 "Performance", Folklore, Cultural Performances, and Popular Entertaiments: A Communications-Centered Handbook, pp. 41-49, Richard Bauman (ed.). Nueva York: Oxford University Press.

1975 "Verbal Art as Performance", American Anthropologist, 77 (2): 290-311.

Brody, Jill

1988 "Incipient Literacy: From Involvement to Integration in Tojolabal Maya", Oral Tradition, 3 (3): 315-352. 
Chica, María Cruz La

2017 Narrativa de tradición oral maya tojolabal. Madrid: Marcial Pons, Instituto Universitario de Investigación en Estudios Latinoamericanos.

Corrigan, Roberta, Edith Moravcsik, Hamid Ouali y Kathleen Wheatley

2009 "Introduction. Approaches to the Study of Formulae", Formulaic Language. Vol. 1. Distribution and Historical Change, pp. XI- XXIV, Roberta Corrigan, Edith A. Moravcsik, Hamid Ouali, Kathleen M. Wheatley (eds.). Amsterdam: John Benjamins.

Curiel, Alejandro

2016 "Estructura narrativa y evidencialidad en tojolabal", tesis de doctorado en Estudios Mesoamericanos. México: Universidad Nacional Autónoma de México, Posgrado en Estudios Mesoamericanos, Facultad de Filosofía y Letras, Instituto de Investigaciones Filológicas.

Finnegan, Ruth

1992 Oral Traditions and the Verbal Arts: A Guide to Research Practices. Londres: Routledge.

Gómez Hernández, Antonio, María Rosa Palazón y Mario Humberto Ruz (eds.)

1999 Ja slo'il ja kaltziltikoni' = Palabras de nuestro corazón: mitos, fábulas y cuentos maravillosos de la narrativa tojolabal. México: Universidad Nacional Autónoma de México, Universidad Autónoma de Chiapas.

González, Aurelio

2003 El Romancero en América. Madrid: Síntesis.

Instituto Nacional de Estadística y Geografía (INEGI)

2016 "Estadísticas a propósito del Día Internacional de los Pueblos Indígenas", Sala de Prensa, 5 de agosto del 2016, <http://www.inegi.org.mx/saladeprensa/aproposito/2016/indigenas2016_0.pdf> [consultado en línea el 23 de octubre de 2018].

Instituto Nacional de Lenguas Indígenas (INALI)

2010a Catálogo de las lenguas indígenas nacionales: Variantes lingüísticas de México con sus autodenominaciones y referencias geoestadísticas, < https://site.inali.gob.mx/ pdf/catalogo_lenguas_indigenas.pdf > [consultado en línea el 23 de octubre de 2018].

2010b Indicadores básicos de la agrupación tojolabal 2010, <https://site.inali.gob.mx/ Micrositios/estadistica_basica/estadisticas2010/pdf/agrupaciones/tojolabal. pdf $>$ [consultado en línea el 23 de octubre de 2018].

Irwin, Bonnie D.

1995 "What's in a Frame? The Medieval Textualization of Traditional Storytelling", Oral Tradition, 10(1): 27-53. 
Jakobson, Roman

1974 "Lingüística y poética”, Ensayos de lingüística general, pp. 347-395. Barcelona: Seix Barral.

Lenkersdorf, Carlos

2005 Tojolabal para principiantes. Lengua y cosmovisión mayas en Chiapas. México: Plaza y Valdés.

2010 B'omak'umal tojol'ab'al-kastilla. Diccionario tojolabal-español, idioma mayense de Chiapas, vol. 1, <http://www.rebelion.org/docs/123766.pdf> [consultada el 25 de octubre de 2018].

López Moya, Martín de la Cruz

2010 Hacerse hombres cabales. Masculinidad entre los tojolabales. México: Centro de Investigaciones y Estudios Superiores de Antropología Social, Universidad de Ciencias y Artes de Chiapas.

Neethling, Siebert Jacob

1982 "The Interpretation of Opening-Closing Formulas in Xhosa Folktales", South African Journal of African Languages, 2: 1-14. DOI: 10.1080/02572117.1982.10596500

Pardo Abril, Neyla Graciela

1998 "Etnografía del habla: una perspectiva del análisis del lenguaje”, Forma y función, 11: 149-160.

Pawley, Andrew

2009 "Grammarians' Languages versus Humanists' Languages and the Place of Speech Act Formulas in Models of Linguistic Competence", Formulaic Language. Distribution and Historical Change, vol. 1, pp. 3-26, Roberta Corrigan, Edith A. Moravcsik, Hamid Ouali, Kathleen M. Wheatley (eds.). Amsterdam: John Benjamins.

Sanfilippo, Marina

2007 "Si cunta e s'arriccunta: las fórmulas de apertura y cierre en la narración oral”, Revista de Dialectología y Tradiciones Populares, LXII (2): 135-163. DOI: 10.3989/rdtp.2007.v62.i2.38

María-Cruz La Chica Delgado. Española. Licenciada en Filología Hispánica por la Universidad Complutense de Madrid, maestra y doctora en Literatura Hispanoamericana por la misma universidad. Actualmente realiza una estancia posdoctoral en el Centro de Estudios Mayas del Instituto de Investigaciones Filológicas de la unAm, y es investigadora del Instituto Universitario de Estudios Latinoamericanos de la Universidad de Alcalá. Sus especialidades son la tradición oral, la narrativa de tradición oral tojolabal, los derechos humanos y los estudios de género. Su proyecto en curso se titula “El Sombrerón: una visión literaria del 'otro' en la 
tradición oral de Chiapas". Entre sus últimas publicaciones se encuentran "El Sombrerón. Una visión literaria del 'otro' en la tradición oral tojolabal”, "La mujer indígena a la sombra de la diversidad" y Narrativa de tradición oral maya-tojolabal. mlachicadelgado@gmail.com 